\title{
Proceeding
}

Supplementary Issue: Winter Conferences of Sports Science. Costa Blanca Sports Science Events, 24 April 2020. Alicante, Spain.

\section{Engagement and tennis: The applicability of occupational psychology to the world of sport}

\author{
FABIO SCAMARDELLA , VALERIA CASILLO, POMPILIO CUSANO
}

Department of Sport Sciences and Well-being, Parthenope University, Naples, Italy

\begin{abstract}
The working activity, as well as the sports one, foresees that results have to be achieved and be decided/evaluated by others, a personal physical and mental effort is required in a well-defined time and space, constraints and limitations established by the nature of the tasks have to be overcome, and a consistent and defined part of one's own time has to be employed. The aim of this research is to demonstrate how work phenomena (specifically work engagement) can be conveyed to the world of sport, highlighting the applicability of occupational psychology also in a sports context.

Keywords: Sport; Engagement; Tennis; Goal-setting.

\section{Cite this article as:}

Scamardella, F., Casillo, V., \& Cusano, P. (2020). Engagement and tennis: The applicability of occupational psychology to the world of sport. Journal of Human Sport and Exercise, 15(2proc), S173S176. doi:https://doi.org/10.14198/jhse.2020.15.Proc2.07
\end{abstract}

Corresponding author. University of Naples "Parthenope", Italy.

E-mail: fabio.scamardella@uniparthenope.it

Supplementary Issue: Winter Conferences of Sports Science. Costa Blanca Sports Science Events, 24 April 2020. Alicante, Spain.

JOURNAL OF HUMAN SPORT \& EXERCISE ISSN 1988-5202

(c) Faculty of Education. University of Alicante

doi:10.14198/jhse.2020.15.Proc2.07 


\section{INTRODUCTION}

The object of the study of occupational psychology concerns the recognition and demonstration of how work activity is developed through the body's response to external and internal stimuli. The latter are the expression of a complex combination of expectations, intentions, intentions, values and purposes, in which people actively interact with the social and technical context by confronting themselves with their explicit and implicit demands, in order to achieve the expected result.

The working activity, as well as the sports one, is characterized by the fact that, in most cases, results have to be achieved and be decided/evaluated by others, a personal physical and mental effort is required in a well-defined time and space, constraints and limitations established by the nature of the tasks have to be overcome, and a consistent and defined part of one's own time has to be employed. These forms of constraint, which generally characterize the working activity, must also be taken into consideration in order to understand the many personal and situational factors that influence the orientation, modulation and definition of the effective action strategies.

They are applied in a specific context where work is redefined and reconfigured as a set of specific tasks. If the different elements defining the person's effective working area are not taken into account, there is the risk of missing the opportunity to understand what it is like to develop working activities, to learn how to carry them out in the best possible way, to preserve one's own well-being even in difficult conditions, to achieve the personal and social goals attributed to work, and to avoid counterproductive and unexpected effects.

\section{METHODS}

All the physical, technical, social and organizational aspects of work that reduce the pressure and the psychological cost of work demands allow easily reaching the objectives and stimulating the worker's personal and professional growth, by affecting their state of engagement. In fact, these aspects serve as extrinsic and intrinsic motivational factors, since they are tools to achieve the expected results of the previously planned goal-setting. This is considered to be particularly important when dealing with difficult tasks in complex performance environments. In this direction, the sports context taken into consideration is the tennis world. The research was carried out during the whole "2019 Italian Women's Serie A2 Team Championships" and involved about 80 athletes. The data of the operational proposal were collected through the administration of a structured questionnaire, consisting of a first autobiographical part, and a second part with a specific survey. The latter was structured "ad hoc" for the analysis of contextual factors: the support of specific professional figures (personal coach, physical trainer, nutritionist, sports psychologist), the analysis of the sports facility at their disposal (type of facility, number of courts available, gym/athletic work areas, types of training field), and items closely related to the goal setting.

\section{RESULTS}

As far as the personal data of the sample obtained from the questionnaires are concerned, it is worth noting that the average age of the athletes was 22 years old, of which $33 \%$ came from Northern Italy, $46 \%$ from Central Italy and only $21 \%$ from Southern Italy. As for the athlete's educational level, $70 \%$ of the sample held a secondary school diploma, while $30 \%$ held at least a Bachelor's degree. The technical ranking according to the parameters of the Italian Tennis Federation was on average 2.4, with a daily average of approximately 4 training hours. On the other hand, the data obtained from the questionnaires concerning the analysis of the sports training facility and its characteristics showed an average of 9 tennis courts available for technical 
training including various surfaces (clay courts, hard courts, and grass courts). In addition, the athletes stated that $60 \%$ of these facilities had indoor courts for the winter season, while $40 \%$ of the facilities taken into consideration did not have this feature. According to $65 \%$ of the sample, in these facilities there were no sports courts dedicated to athletic preparation, while $35 \%$ had ad hoc spaces. As for the professional profiles of reference to the concept of engagement, $54 \%$ of the athletes declared that they did not have a personal coach/technician, and $60 \%$ stated they were supported by a physical trainer. The mostly absent figure in these facilities turned out to be that of the nutritionist and of the sports psychologist $(66 \%$ of athletes were not supervised by a nutritionist, and $70 \%$ said they did not benefit from psychological counselling). However, the majority of the athletes stated that, in every training session, they were supervised by their facility technician (65\%). Finally, the research area dedicated to the achievement of objectives (goal - setting) made $100 \%$ of the athletes agree on the fact that, if a greater number of professional figures were present in the sports facilities of reference, the sports results would improve considerably. In addition to the research item concerning the growth of motivation for competitive practice, all athletes (100\%) agreed on the fact that the presence of more professionals would improve sports results. Finally, $80 \%$ of the surveyed athletes declared that they were satisfied with their training organization.

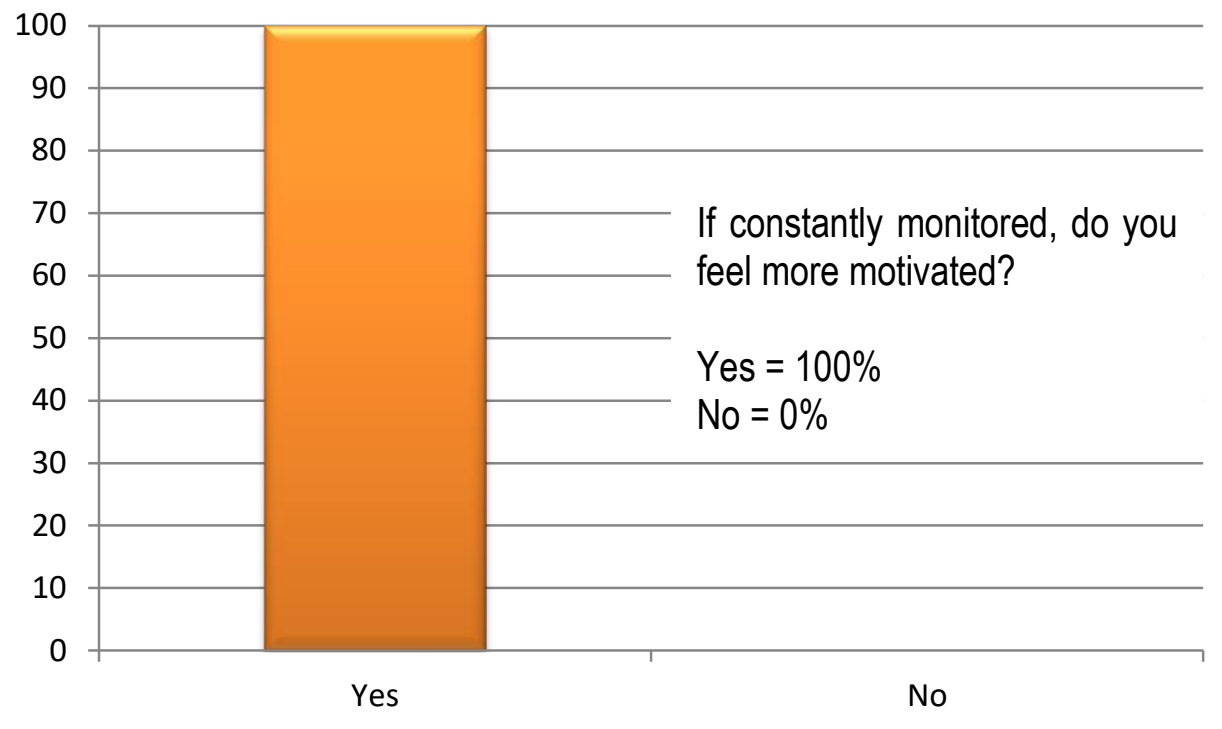

Figure 1. Results.

\section{CONCLUSIONS}

The analysis of the results reveals more data relevant to the initial research hypotheses, i.e. the direct correlations between context, performance and goal-setting factors.

First of all, the facility is of fundamental importance: the number of courts, the surface area of the playing fields and the possibility of having indoor spaces for the winter season have a positive impact on the increase in sports performance. Likewise, the possibility of training in ad hoc spaces for physical preparation becomes a fundamental factor.

Moreover, in terms of physical preparation, from the analysis of the results, the figure of the athletic trainer is necessary to achieve and increase performance. Therefore, a fundamental requirement of the engagement 
in the sports field is the constant presence of the structure technician; according to the analysis of the data, this figure increases the motivation to the performance itself. In addition, it was found that the most successful athletes (ranking) during daily training are supported by highly qualitative context factors, compared to lower level athletes. While the former aim at ambitious ranking goals, the latter are limited to a mere confirmation of the current ranking. Finally, as further support to the research, $100 \%$ of the players expressly declared a strong correlation between motivation and context factors, thus confirming the starting hypothesis. In terms of operational consequences, therefore, as it happens in the working context, it becomes important that every athlete, in addition to having an effective baggage of personal resources, must be surrounded by qualitative context factors that, by developing a greater motivation, can help them achieve an optimal performance.

\section{REFERENCES}

Anolli L., Legrenzi P. (2003). Psicologia Generale, II Mulino Editor, Bologna.

Blau P.M. (1964). Exchange and Power in Social Life, John Wiley and Sons, New York.

Cardona P., Lawrence B.S., Bentler P.M. (1986) The influence of social and work exchange relationships on organizational citizenship behaviour. Group and Organization Management. https://doi.org/10.1177/1059601103257401

Chaplain R.P., (2008). Stress and psychological distress among trainee secondary teachers in England. Educational Psychology. https://doi.org/10.1080/01443410701491858

Cortese C.G. (2005). Motivare, Raffaello Cortina Editor, Milan.

Cox R.H. (2007). Sport Psychology, Mc Graw - Hill Editor, New York.

Cramer D. (1996). Job Satisfaction and Organizational Continuance commitment: A Two-Wave Panel Study. Journal Of Organizational Behavior. https://doi.org/10.1002/(sici)10991379(199607)17:4<389::aid-job755>3.0.c0;2-2

Cummings L.L., Bmmiley P. (1996). The organizational trust inventory (Oti): Development and Validation, In R.M. Kramer, T.Tyler (Eds.). Trust in organizations: Frontiers of theory and research, Sage Publications. Curry J .P., Wakefield D.S.,(1986) On the causal ordering of job satisfaction and organizational commitment. Academy of Management Journal. https://doi.org/10.4135/9781452243610.n15

Fraccaroli F., Sarchielli G. (2005). Introduzione Alla Psicologia Del Lavoro, II Mulino Editor, Bologna.

Sarchielli G. (2003). Psicologia Del Lavoro, II Mulino Editor, Bologna.

Seligman M. (1992). Helpless: On Depression, Development And Death, W.H. Freeman, New York. Seligman M. (2003). La Costruzione Della Felicità, Sperling e Kupfer Editor, Milan. Watson J., (1928), Psychological Care Of Infant And Child, Norton Editor, New York.

\section{(2) $\odot \Theta \Theta$}

This work is licensed under a Attribution-NonCommercial-NoDerivatives 4.0 International (CC BY-NC-ND 4.0). 